\title{
Myths about halitosis
}

\begin{abstract}
Halitosis or bad breath is a common problem that affects nearly $25 \%$ of the population. More than three quarters of the problems originate in the oral cavity. The main causes here are chronic or acute periodontitis/gingivitis and tongue coating. $10 \%$ of the odors are causes by ENT problems, such as tonsillitis and/or post-nasal drip. The final remaining $5 \%$ finds their origin in different medical/systemic conditions and disorders (e.g. diabetes, hepatitis or uremia). Almost $90 \%$ of all halitosis cases can be solved, mostly by a proper dental/ periodontal treatment and a lifelong meticulous oral hygiene. Halitosis is still a large taboo in our contemporary society. Although it often bothers close relatives, friends or social and professional contacts, it is not an easy topic to discuss directly with the affected person(s). To get around the subject, several (false) myths are called to life. This article will discuss the major myths around bad breath in more detail.
\end{abstract}

Volume 5 Issue 2 - 2016

\section{Curd Bollen}

Department of Periodontology Halitosis Implantology, Oral Clinical Center, Netherlands

\author{
Correspondence: Curd Bollen, Department of \\ Periodontology Halitosis Implantology, Oral Clinical Center, \\ Eyckholtstraat I-6II6 BR Roosteren, Netherlands, \\ Emaildr.curdbollen@gmail.com
}

Received: August 25, 2015 | Published: September 15, 2016

\section{Introduction}

Bacteria that live in our mouths produce odors due to the digestion of proteins and sulphur containing substrates present in the oral cavity. ${ }^{1}$ These produced odors are called Volatile Sulfur Compounds (VSC) since they mostly contain sulphuric components. ${ }^{2}$ The most important volatile sulphur compounds involved in oral malodor are hydrogen sulphide $(\mathrm{H} 2 \mathrm{~S})$, methyl mercaptan $(\mathrm{CH} 3 \mathrm{SH})$ and dimethyl sulphide $((\mathrm{CH} 3) 2 \mathrm{SH})$. Also other molecules can be involved in this bacterial degradation process; the diamines indole and skatole or the polyamines cadverin and putrescin (Table 1). The most important substrates in this VSC-production are cysteine, cystine and methionin.

Table I Main volatile molecules contributing to oral malodor

I.Volatile Sulphur Compounds (VSC):
Methyl mercaptan: $\mathrm{CH} 3 \mathrm{SH}$
Hydrogen sulphide: $\mathrm{H} 2 \mathrm{~S}$
Dimethyl sulphide: $(\mathrm{CH} 3) 2 \mathrm{SH}$
2. Diamines:
Putrescine: $\mathrm{NH} 2(\mathrm{CH} 2) 4 \mathrm{NH} 2$
Cadaverine: $\mathrm{NH} 2(\mathrm{CH} 2) 5 \mathrm{NH} 2$
Butyric acid: $\mathrm{CH} 3 \mathrm{CH} 2 \mathrm{CH} 2-\mathrm{COOH}$
Propionic acid: $\mathrm{CH} 3 \mathrm{CH} 2-\mathrm{COOH}$
Valeric acid: $\mathrm{C} 5 \mathrm{H} 10 \mathrm{O} 2$
3. Phenyl Compounds:
Indole: $\mathrm{C} 8 \mathrm{H} 7 \mathrm{~N}$
Skatole: $\mathrm{C} 9 \mathrm{H} 9 \mathrm{~N}$
Pyridine: $\mathrm{C} 5 \mathrm{H} 5 \mathrm{~N}$
4. Alcohols:
I-propoxy-2-propanol
5.Alkalines:
2-methy-propane
6. Nitrogen-Containing Compounds:
Urea: (NH2)2CO
Ammonia: $\mathrm{NH} 3$
7. Ketones

The main substrate for the skatole and indole production is tryptofan, whereas lysine and ornithine are the basis for the putrescin and cadaverin production. The responsible micro-organisms that produce these VSC are anaerobic bacteria, the same species that are found in chronic and acute periodontitis (Table 2). ${ }^{3}$ The most common niches in the mouth were these bacteria hide, are: in (inflamed) periodontal pockets, in interdental spaces, in "traps" such as in cariogenic cavities and under ill fitting crowns or fillings, in the coating of the tongue and on removable dental appliances. ${ }^{4}$ Tongue coating has been found to be the largest contributor to the phenomenon, since foods remnants and exfoliated cells, the "food" for the sulphur-producing bacteria, are easily captured on the large rough surface of nearly $25 \mathrm{~cm} 2 .{ }^{5}$

Table 2 Bacteria responsible for Vsc-production

\begin{tabular}{ll}
\hline H2S From Cysteine & H2S From Serum \\
\hline Peptosteptococcus anaerobius & Prevotella intermedia \\
Micros prevotii & Prevotella loescheii \\
Eubacterium limosum & Porphyromonas gingivalis (BANA +) \\
Bacteroides spp. & Treponema denticola (BANA -) \\
Centipedia periodontii & \\
CH3SH From Methionine & CH3SH From Serum \\
Fusobacterium nucleatum & Treponema denticola (BANA +) \\
Fusobacterium periodonticum & Porphyromonas gingivalis (BANA +) \\
Eubacterium spp. & Porphyromonas endodontalis \\
Bacteroides spp. & \\
Other Involved Bacteria & \\
Prevotella melaninogenica & Treponema forsythensis \\
Tanerella forsythensis & Centipeda periodontii \\
Eikenella corrodens & Atopobium parvulum \\
Solobacterium moorei & \\
\hline
\end{tabular}

\section{Taboo}

A public investigation in The Netherlands showed that halitosis was 1 of the 100 biggest human overall taboos. ${ }^{6}$ This was also stated recently by Schmidt and co-workers. ${ }^{7}$ But the amount of epidemiological research on bad breath is limited, due to the fact of the reliability of discussing the topic. There are different reasons for this lack of scientific data. First, there is the difference in cultural 
and racial appreciation of odors (as there is for patients and for investigators). ${ }^{8}$ Secondly there is absence of uniformity in evaluation methods. Halitosis is still a large taboo. It cannot only lead to social isolation and psychological disorders, but it can also be the indication for an underlying systemic disease. ${ }^{9}$ In extreme cases, even suicide of patients is reported due to their problem. ${ }^{10}$ As often happens in society, taboos can lead to myths. The difference between a myth and a taboo is that a myth is a traditional story which embodies a belief regarding some fact or phenomenon of experience, and in which often the forces of nature and of the soul are personified; a sacred narrative regarding a god, a hero, the origin of the world or of a people, etc. Whereas a taboo is an inhibition or ban, that results from social custom or emotional aversion.

\section{Myths}

Halitosis comes from the stomach: The most common misperception is that bad breath arises from the stomach. This is not true, since there are a series of valves in our stomach and esophagus that block the regurgitation of our food. These valves also block any stomach odors from coming back up into the esophagus, our throats, and out our mouths or nose. Only an extremely small percentage of bad breath problems may be due to stomach and digestive problems. The esophagus can only be the origin of malodor in very specific cases as when Zenker's diverticulum is present. The incidence of this phenomenon is less than $0,1 \%$ and it can only be diagnosed in patients over 65 years of age. ${ }^{11}$ Only when extreme severe regurgitation is determined in these patients, halitosis will be present. ${ }^{12}$ Symptomatically, coughing, postnasal drip, pyrosis, irritations and ulcerations of the esophagus and halitosis will be detected. PH-monitoring is used for diagnosis. When the diagnosis is missed, carcinomatic deterioration can occur. Stomach infections with Helicobacter pylori can cause peptic ulcers. There is no correlation found between these ulcers and halitosis. ${ }^{13}$

It's easy to tell if one owns breathe smells: Many people believe they can smell their own breath odor. Unfortunately, we can absolutely not tell if our breath smells because we become accustomed to our own odors. ${ }^{14}$ In many cases, we do not produce bad breath until we talk. After all, bad breath originates near the back of the mouth (tongue dorsum) and is expired only when we speak. How can we eventually tell if our breath smells? The best ways is to ask a trusted person smell it for you on a distance of nearly $30 \mathrm{~cm}$ whilst speaking. You can also use some interdental floss on yourself and give that a smell. ${ }^{9}$ The most accurate assessment of bad breath is performed by a dentist/ periodontist using a device (Halimeter ${ }^{\circledR}$ or Oral Chroma ${ }^{\circledR}$ ). These machines measure the amount of volatile sulfur compounds (VSCs) in the breath. Well trained halitosis-specialists can however determine the odor intensity by sniffing at a breath (organoleptical scoring). ${ }^{9}$ The commercial available handheld bad breath detectors have no significant value in detecting peoples own bad breath. They mostly give false negative results. ${ }^{15}$

There is no cure for halitosis: This is absolutely untrue. Several studies indicate a $90 \%$ success rate in curing bad breath. ${ }^{4}$ The most efficient therapy is depending on the origin of the problem. In case of a periodontal origin, a periodontal treatment (including tongue cleaning) will give an excellent result, whereas if the odor originates of the ENT region, a tonsillectomy can eventually causes relief. ${ }^{6-16}$ Only in the case of halitophobia, a clear cut result is unlikely. ${ }^{17}$ Halitophobia is the fear of halitosis: the fear of having bad breath that others will find offensive. Moreover 0.5 to $1 \%$ of the adult population is affected with this problem in their social live. These patients consider having bad breath, don't have it, but get not convinced of this during diagnosis and therapy.Non-real halitosis or halitophobia is understood by the compulsive idea to suffer from bad breath and to irritate others by this. This compulsive idea can change the complete pattern of behaviour of these patients which in itself can lead to self-isolation and even to suicide. ${ }^{17}$ Consultation hours for halitosis should be prepared for patients with non-real halitosis and build up corresponding interdisciplinary contacts..$^{10}$ The "treatment" of this kind of patients is rather impossible, since they are not into the arguments stated by the physician or dentist. Mostly, these patients hop from clinic to clinic and from specialist to specialist, in the hope to find an argument for their self-esteemed problem. Imagined halitosis is poorly documented in the psychiatric literature as proved by Malasi and co-workers. ${ }^{18}$ It is perhaps best thought of as a symptom rather than as a specific syndrome (a collection of symptoms that co-vary together). Many of the cases with imagined halitosis described in the literature resemble the psychiatric syndrome of social phobia. ${ }^{19}$

Brushing or scraping the tongue is enough to keep the bad breath away: Scraping the tongue only removes a thin layer of a deep accumulation of bacteria, dead skin cells, dead blood cells, food and debris which make up a major cause of the odor of bad breath. But a lot of bacteria are also hidden in other niches in the mouth. Therefore good dental hygiene (including brushing, interdental cleaning and tongue cleaning) helps eliminate bad breath. ${ }^{20}$ Unfortunately, most people do not properly brush their teeth: it takes nearly three minutes to completely brush all tooth surfaces yet most people spend only 30 to 45 seconds brushing their teeth. Consequently, they consistently miss tooth surfaces where bacteria are allowed to proliferate and create odorous volatile sulfur compounds. But excessive brushing will not help to eliminate the breath condition: too much brushing can dry the mouth, thus increasing the halitosis problem. Excessive brushing can also damage the teeth and gums over time, creating new niches for odor producing bacteria to adhere.

Mouthwashes, mints, and gums can eliminate halitosis permantly: Companies that sell these products would like us to believe this; however, most products simply cover up the malodor with a stronger, more pleasant-smelling odor for a few short minutes at best. This is true of every product that has a moderate-to-strong taste or odor. In addition, most even contain some type of sugar that feed the bacteria, creating even more odor at the end! When sugar-free chewing gum is used, a temporary halitosis-reducing effect can be detected. ${ }^{21}$ In fact, most conventional mouthwashes can really contribute to bad breath formation. This is also because mouthwashes contain often a high percentage of alcohol which tends to dry out the mouth thus increasing the volatilization of breath odors. Bacteria responsible for creating bad breath grow much better in drier mouths. ${ }^{22}$ But there are of course mouthwashes with "active" ingredients that can have some beneficial effects in reducing oral malodor in both short- and longer-term studies. The most compelling evidence is provided for chlorhexidine mouthwashes, and those that contain a combination of cetyl pyridinum chloride and zinc. ${ }^{23}$

Foods cause bad breath: While it's true that onions, garlic and cauliflower, can taint the breath, they are only transitory and not responsible for ongoing halitosis..$^{24}$ This odor can be easily eliminated by avoiding to take that particular food. Moreover, the odors they produce are not of the "sulfur" type commonly seen in true halitosis conditions, and generally are not as offensive. Of course some food particles will, however, penetrate the coatings on the tongue or are 
absorbed in our intestines and be finally absorbed into the bloodstream to be expelled in the breath from our lungs. Here the "unpleasant" compounds are exhaled as we breathe causing our breath to smell. On the other hand, chronic bad breath results when bacteria in the mouth break down left over food particles creating odorous sulfur particles. Recently, Much and Barringer studied the deodorization of garlic breath by food and food componenents. Enzymatic deodorization involved oxidation of polyphenolic compounds by enzymes, with the oxidized polyphenols causing deodorization. ${ }^{25}$ The primary goal in this case is not a change in diet but a reduction in the number of odor causing bacteria in the mouth. This can be done with proper brushing, flossing, and cleaning of the tongue with a tongue cleaner (tongue scraper) (Figure $1 \& 2$ ). ${ }^{9}$

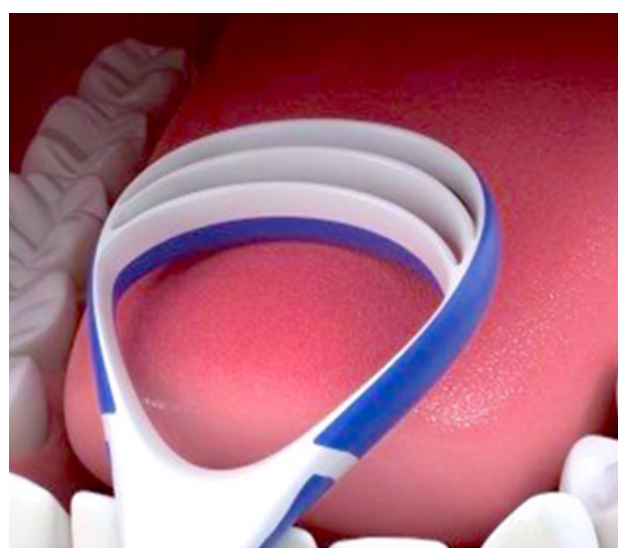

Figure I Tongue cleaning.

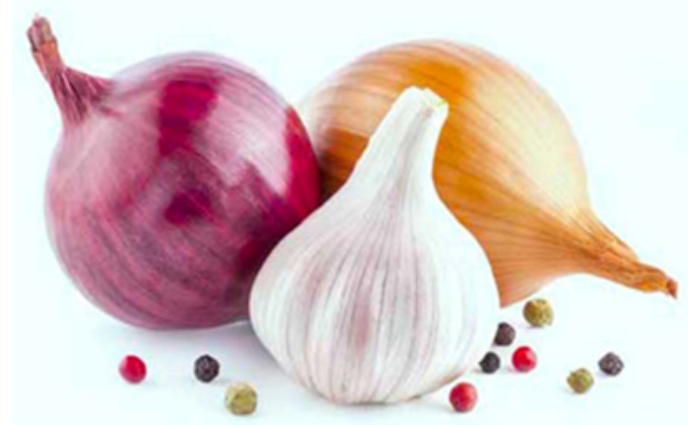

Figure 2 Garlic and onions cause temporaily bad breath.

\section{Conclusion}

In general we can conclude that the incidence of halitosis originating from the gastro-intestional tract is neglectable and that food only temporarily can contribute to bad breath. Although people often pretend they can smell their own breath, it is almost impossible to smell your own bad breath yourself. $90 \%$ of the halitosis cases can be cured, but tongue cleaning alone is not enough to eliminate halitosis; an extended oral hygiene regimen is always required. Moreover, a mouthwash as a single potion to get rid of halitosis is never sufficient. Only for halitophobia patients there is no real "cure" available. Here psychology needs to interfere!

\section{Funding}

None.

\section{Acknowledgments}

None.

\section{Conflicts of interest}

Author declares that there is no conflict of interest.

\section{References}

1. Greenman J, Duffield J, Spencer P, et al. Study on the organoleptic intensity scale for measuring oral malodor. $J$ Dent Res. 2004;83(1):81-85.

2. Tonzetich J, Richter VJ. Evaluation of volatile odoriferous components of saliva. Arch Oral Biol. 1964;9:39-46.

3. Bosy A, Kulkarni GV, Rosenberg M, et al. Relationship of oral malodor to periodontitis: evidence of independence in discrete subpopulations. $J$ Periodontol. 1994;65(1):37-46.

4. Delanghe G, Ghyselen J, Bollen C, et al. An inventory of patients' response to treatment at a multidisciplinary breath odor clinic. Quintessence Int. 1999;30(5):307-310.

5. Roldán S, Herrera D, Sanz M. Biofilms and the tongue: therapeutical approaches for the control of halitosis. Clin Oral Investig. 2003;7(4):189-197.

6. Ansai T, Takehara T. Tonsillolith as a halitosis-inducing factor. Br Dent $J$. 2005;198(5):263-264.

7. Schmidt J, Krause F, Haak R. Halitosis: measurement in daily practice. Quintessence Int. 2015;46(7):633-641.

8. Rayman S, Almas K. Halitosis among racially diverse populations: an update. Int J Dent Hyg. 2008;6(1):2-7.

9. Bollen CM, Beikler T. Halitosis: the multidisciplinary approach. Int $J$ Oral Sci. 2012;4(2):55-63.

10. Nagel D, Lutz C, Filippi A. Halitophobia-an under-recognized clinical picture. Schweiz Monatsschr Zahnmed. 2006;116(1):57-64.

11. Sooklal S, Sohagia A. Undigested food on awakening with persistent halitosis. BMJ Case Rep. 2014;pii:bcr2014204895.

12. Struch F, Schwahn C, Wallaschofski H, et al. Self-reported halitosis and gastro-oesophageal reflux disease in the general population. $J$ Gen Intern Med. 2008;23(3):260-266.

13. Werdmuller BF, Van der Putten TB, Balk TG, et al. Clinical presentation of Helicobacter pylori-positive and -negative functional dyspepsia. $J$ Gastroenterol Hepatol. 2000;15:498-502.

14. Eli I, Koriat H, Baht R, et al. Self-perception of breath odor: role of body image and psychopathologic traits. Percept Mot Skills. 2000;91(3 pt 2):1193-1201.

15. Grover HS, Blaggana A, Jain Y, et al. Detection and measurement of oral malodor in chronic periodontitis patients and its correlation with levels of select oral anaerobes in subgingival plaque. Contemp Clin Dent. 2015;6(suppl 1):S181-S187.

16. Erovic Ademovski S, Mårtensson C, Persson GR, et al. The effect of periodontal therapy on intra-oral halitosis: a case series. $J$ Clin Periodontol. 2016;43(5):445-452.

17. Yaegaki K, Coil JM. Examination, classification and treatment of halitosis: clinical perspectives. $J$ Canad Dent Assoc. 2000;66(5):257-261.

18. Malasi TH, El-Hilu SM, Mirza IA, et al. Olfactory delusional syndrome with various aetiologies. Br J Psychiatry. 1990;156:256-260.

19. Bohn P. Imagined halitosis: a social phobia symptom? J Calif Dent Assoc. 1997;25(2):161-164.

20. Tonzetich J, Ng SK. Reduction of malodor by oral cleansing procedures. Oral Surg Oral Med Oral Pathol. 1976;42(2):172-181.

21. Shiyao L, Yamei X, Deyu H. Anti-halitosis effect of sugar-free chewing gum. Hua Xi Kou Qiang Yi Xue Za Zhi. 2015;33(2):166-168. 
22. Roldán S, Herrera D, Santa-Cruz I, et al. Comparative effects of different chlorhexidine mouth-rinse formulations on volatile sulphur compounds and salivary bacterial counts. J Clin Periodontol. 2004;31(12):1128-1134.

23. Blom T, Slot DE, Quirynen M, et al. The effect of mouthrinses on oral malodor: a systematic review. Int J Dent Hyg. 2012;10(3):209-222.

24. Borrelli F, Capasso R, Izzo AA. Garlic (Allium sativum L.): adverse effects and drug interactions in humans. Mol Nutr Food Res. 2007;51(11):1386-1397.

25. Munch R, Barringer SA. Deodorization of garlic breath volatiles by food and food components. J Food Sci. 2014;79(4):C526-C533.
26. Blom T, Slot DE, Quirynen M, et al. The effect of mouthrinses on oral malodor: a systematic review. Int J Dent Hyg. 2007;10(3):209-222.

27. Goldberg S, Kozlovsky A, Gordon D, et al. Cadaverine as a putative component of oral malodor. J Dent Res. 1994;73(6):1168-1172.

28. Claus D, Geypens B, Rutgeers P, et al. Where gastroenterology and periodontology meet: determination of oral volatile organic compounds using closed-loop trapping and high-resolution gas chromatography-ion trap detection. In: van Steenberghe D \& Rosenberg M, (Ed). Bad breath: a multidisciplinary approach. Leuven University Press: Belgium, Europe; 1996. $15-28$ p. 